\title{
Preparation of Iron Doped Hydroxyapatite Microsphere by Mist Process
}

\author{
Mitsutaka Sato ${ }^{1}$ and Atsushi Nakahira ${ }^{2,3}$ \\ ${ }^{1}$ Institute for Materials Research, Tohoku University, Sendai 980-8577, Japan \\ ${ }^{2}$ Osaka Prefecture University, Sakai 599-8531, Japan \\ ${ }^{3}$ Kansai Center for Industrial Materials Research, Tohoku University, Sakai 599-8531, Japan
}

\begin{abstract}
Hydroxyapaite and $\mathrm{Fe}$ doped hydroxyapatite microsphere were prepared by mist process using $\mathrm{Ca}\left(\mathrm{NO}_{3}\right)_{2}, \mathrm{FeCl}_{3}$ and $\left(\mathrm{NH}_{4}\right)_{2} \mathrm{HPO}_{4}$ aqueous solutions, and the effects of the preparation condition and Fe doping on the crystal phase, microstructure and other properties were investigated. From XRD analysis, obtained powders were HAp in a single phase at the $\mathrm{Ca} / \mathrm{P}$ ratio from 1.5 to 2.0 , independent from preparation temperature and gas flow rate. In the case of the $\mathrm{Ca} / \mathrm{P}$ ratio of 1.0 , obtained powder was mixed phase of $\mathrm{HAp}$ and $\mathrm{Ca}_{2} \mathrm{P}_{2} \mathrm{O}_{7}$. The crystallinity of powders strongly depended on preparation temperature and flow rate of carrier gas and was enhanced with decreasing flow rate of argon and increasing preparation temperature. The SEM observation suggested that the obtained samples had a fine microsphere consisted of further smaller primary grains. The microsphere size of sample was about $1 \mu \mathrm{m}$, and size distribution was between 0.5 and $5 \mu \mathrm{m}$. [doi:10.2320/matertrans.Y-M2014830]
\end{abstract}

(Received April 16, 2014; Accepted July 23, 2014; Published September 12, 2014)

Keywords: mist process, calcium phosphate, microsphere, drug delivery system

\section{Introduction}

Hydroxyapatite $\left(\mathrm{HAp}, \mathrm{Ca}_{10}\left(\mathrm{PO}_{4}\right)_{6}(\mathrm{OH})_{2}\right)$ has been widely used as artificial bone and coatings of artificial implant in the medical and dental fields because HAp is chief inorganic element of hard tissue, occupying about $70 \%$, and shows excellent biocompatibility and bioactivity. ${ }^{1-3)}$ Since HAP also shows excellent ion exchange ability, the developments of HAp based functional materials have been performed by doping of functional elements that provide a novel properties to HAp. ${ }^{4-12)}$ For example, the doping of $\mathrm{Fe}^{3+}$ and $\mathrm{SiO}_{4}{ }^{4-}$ provides a non-equilibrium of charge balance, and this electrically-charged HAp can be anticipated to use as environmental materials such as water purification and heavy metal ion removal materials. ${ }^{13,14)}$

From these points of view, morphological design for HAp based materials is important in order to obtain its full functions. Especially, HAp microsphere is expected to be a good candidate for use as drug delivery system (DDS) materials and resource powder of 3D printer. Therefore, HAp based microsphere with wide particle size range from submicron to several $\mathrm{mm}$ have been prepared by many kinds of method such as template method, ultrasonic pyrolysis method and aerosol method, so far. ${ }^{15-18)}$

Mist process is a unique technique to obtain powder and film under the atmospheric conditions, analogous to ultrasonic pyrolysis system (USPS) and chemical transport system. Since mist process has advantages of easy-to-use device configuration and many kinds of solution can be used as a precursor, this method has attracted much attention as a safe and economical method. The principle of mist process is that a liquid precursor is atomized by ultrasonic vibrator, and mist solution is transported by carrier gas to a reaction furnace, then mist precursor thermally decomposes and reacts. Therefore, many kinds of oxides film caused by the thermal decomposition and reaction can be obtained by setting a substrate at heating area, and many studies on the preparation of $\mathrm{ZnO}, \mathrm{Al}_{2} \mathrm{O}_{3}$ and $\mathrm{TiO}_{2}$ have been reported, so far. ${ }^{19-22)}$ Besides, oxides powders also can be filtered by setting the exhaust system at the end of heating tube at the same time, and it is expected that the filtered powders had a sphere shape.

In this study, we prepared spherical Fe-doped HAp particles by mist process and investigated the effect of Fedoping and preparation condition such as gas flow rate, the $\mathrm{Ca} / \mathrm{P}$ ratio and preparation temperature on the crystal phase, microstructure and shape of particles.

\section{Experimental Procedure}

$0.1 \mathrm{~mol} / \mathrm{L} \mathrm{Ca}\left(\mathrm{NO}_{3}\right)_{2}, \mathrm{FeCl}_{3}$ and $\left(\mathrm{NH}_{4}\right)_{2} \mathrm{HPO}_{4}$ aqueous solutions were used as starting materials. The $\mathrm{pH}$ of $\mathrm{Ca}$ and Fe mixed solution was adjusted to 8 by $1.0 \mathrm{~mol} / \mathrm{L}$ tris solution, and that of $\mathrm{P}$ solution was adjusted to 12 by $5 \mathrm{~mol} / \mathrm{L}$ $\mathrm{NaOH}$ solution. After controlling $\mathrm{pH}$, they were mixed up each other to become the ratio of $\mathrm{Ca}$ to $\mathrm{P}$ in the range from 1.0 to 2.0. The ratio of $\mathrm{Fe}$ changed from 0 to $5 \mathrm{~mol} \%$ for $\mathrm{Ca}$. The mixed solution was atomized by mist process apparatus. Figure 1 shows a schematic diagram of mist process apparatus. Atomized precursor undergoes drying and nucleation by passing the heated glass tube. Particles were collected by installed exhaust system at the terminal of glass tube. Argon gas was used as a carrier gas, and the flow rate of $\mathrm{Ar}$ was changed from 1 to $5 \mathrm{~L} / \mathrm{min}$. The preparation temperature was changed in the range from 873 to $1073 \mathrm{~K}$, and the preparation time was fixed at $60 \mathrm{~min}$. The detailed

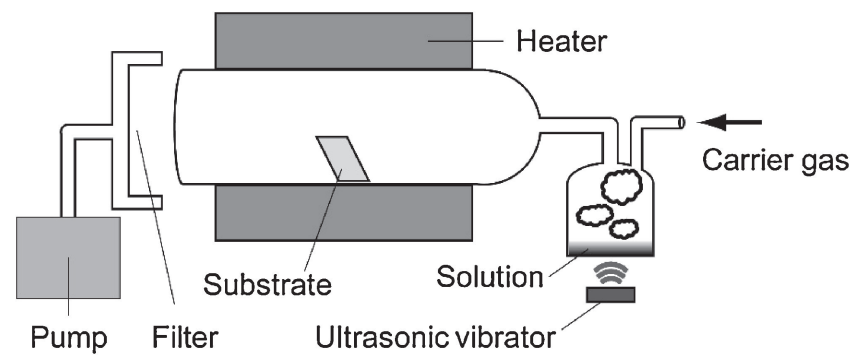

Fig. 1 Schematic diagram of mist process apparatus. 
Table 1 Preparation condition of Ca-P-O powder.

\begin{tabular}{ll}
\hline Precursor & \\
$\mathrm{Ca}\left(\mathrm{NO}_{3}\right)_{2}$ & $0.1 \mathrm{~mol} / \mathrm{L}$ \\
$\left(\mathrm{NH}_{4}\right) \mathrm{HPO}_{4}$ & $0.1 \mathrm{~mol} / \mathrm{L}$ \\
$\mathrm{FeCl}_{3}$ & $0.1 \mathrm{~mol} / \mathrm{L}$ \\
$\mathrm{Ca} / \mathrm{P}$ ratio & $1.0,1.5,1.67,2.0$ \\
Fe ratio & $1,2,5 \mathrm{~mol} \%$ \\
Gas spieces & $\mathrm{Ar}$ \\
Flow rate & $1,3,5 \mathrm{~L} / \mathrm{min}$ \\
Preparation temperature & $873,973,1073 \mathrm{~K}$ \\
Preparation time & $60 \mathrm{~min}$ \\
\hline
\end{tabular}

preparation conditions were listed in Table 1. The crystal phase of samples was determined by X-ray diffraction (XRD) using X-ray diffract meter at $30 \mathrm{kV}$ and $15 \mathrm{~mA}$. All scans were run with $\mathrm{CuK} \alpha$ radiation from $10^{\circ}$ to $60^{\circ}$ at a speed of $4^{\circ} / \mathrm{min}$. The microstructure of sample was observed by field emission scanning electron microscope (FE-SEM, S-4800, Hitachi High-Technologies, Corp.), and the average grain diameter and specific surface area were measured by BELSORP mini (BEL JAPAN, INC.) and laser diffraction particle size analyzer (SALD-2200, Shimadzu Corp.), respectively.

\section{Results}

Figure 2 shows XRD patterns of obtained samples prepared at different $\mathrm{Ca} / \mathrm{P}$ ratio. HAp in a single phase was obtained at the $\mathrm{Ca} / \mathrm{P}$ ratio of 1.67 , and mixed phase of HAp and $\mathrm{Ca}_{2} \mathrm{P}_{2} \mathrm{O}_{7}$ with low crystallinity was obtained at the $\mathrm{Ca} / \mathrm{P}$ ratio of 1.0 , and mixed phase of $\mathrm{HAp}$ and $\mathrm{Ca}(\mathrm{OH})_{2}$ was obtained at the $\mathrm{Ca} / \mathrm{P}$ ratio of 2.0 , respectively.

Figure 3 shows XRD patterns of samples prepared at the $\mathrm{Ca} / \mathrm{P}$ ratio of 1.67 , the preparation temperature of $1073 \mathrm{~K}$, gas flow rate of $3 \mathrm{~L} / \mathrm{min}$ and the $\mathrm{Fe}$-doping ratio from 0 to $5 \mathrm{~mol} \%$. Although the obtained all samples had HAp phase as a main phase, the peaks derived from $\mathrm{Ca}(\mathrm{OH})_{2}$ and $\mathrm{CaClOH}$ phases were observed as a second phase at the Fe ratio of 2 and $5 \mathrm{~mol} \%$.

Figure 4 shows FT-IR spectra of samples prepared at $1073 \mathrm{~K}, \mathrm{Ca} / \mathrm{P}$ ratio of 1.67 , flow rate of $3 \mathrm{~L} / \mathrm{min}$ and $\mathrm{Fe}$ ratio of $0 \mathrm{~mol} \%$ and $1 \mathrm{~mol} \%$. Both samples showed HAp in a single phase as shown in Fig. 3. Obtained spectra showed similar tendency with commercial HAp. There was the $\mathrm{OH}$ stretching band around $3450 \mathrm{~cm}^{-1}$. The $\mathrm{CO}_{3}$ v3 band was observed at around 1500 and $873 \mathrm{~cm}^{-1}$, respectively. The phosphate bands were observed around 1000 and $580 \mathrm{~cm}^{-1}$.

Figure 5 shows SEM images of samples prepared at the different preparation temperature and the ratio of $\mathrm{Fe}$. Obtained HAp powders had microsphere shape consisted from primary particles of about $10 \mathrm{~nm}$ in diameter in all preparation conditions. Although a necking of particle was observed for the HAp microsphere prepared at the $873 \mathrm{~K}$, it was collapsed with increasing the preparation temperature. From the observation of the fragment of HAp microsphere as shown in Fig. 5 (c), it was indicated that the obtained microsphere has a solid structure. In addition, no change in

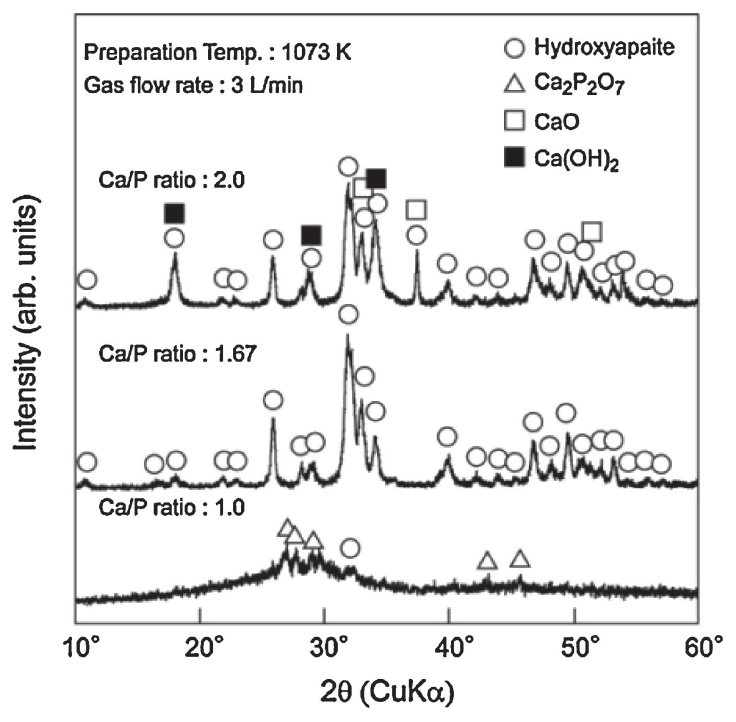

Fig. 2 XRD patterns of samples prepared at preparation temperature of $1073 \mathrm{~K}$, flow rate of Ar gas of $3 \mathrm{~L} / \mathrm{min}, \mathrm{Ca} / \mathrm{P}$ ratio of 1.67 and different Fe ratio.

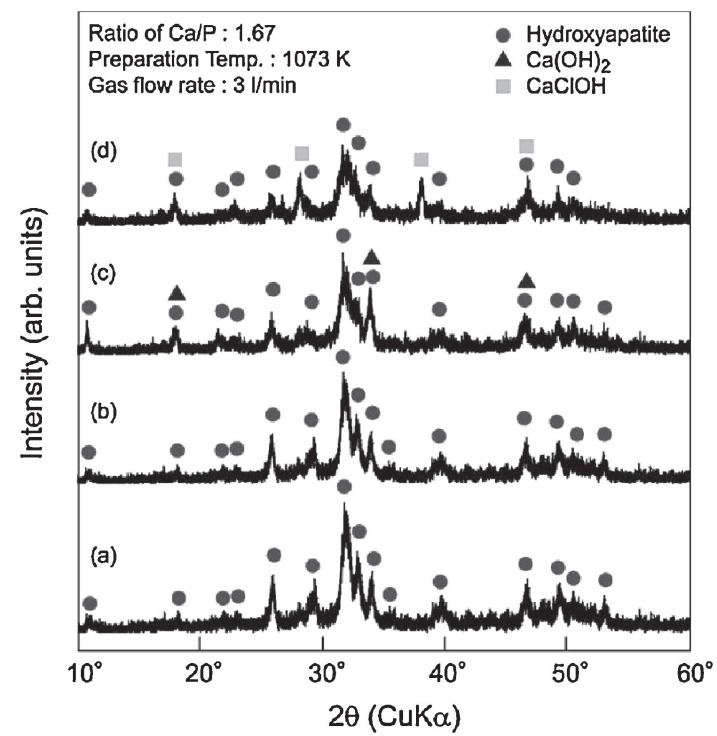

Fig. $3 \mathrm{XRD}$ patterns of samples prepared at preparation temperature of $1073 \mathrm{~K}$, flow rate of $\mathrm{Ar}$ gas of $3 \mathrm{~L} / \mathrm{min}, \mathrm{Ca} / \mathrm{P}$ ratio of 1.67 and different Fe ratio; (a) $0 \mathrm{~mol} \%$, (b) $1 \mathrm{~mol} \%$, (c) $2 \mathrm{~mol} \%$, (d) $5 \mathrm{~mol} \%$.

the morphology was observed by Fe-doping as shown in Fig. 5 (d).

Figure 6 shows grain size distribution of Fe-doped HAp microsphere prepared at preparation temperature between 973 and $1073 \mathrm{~K}$ with the flow rate of 3 and $5 \mathrm{~L} / \mathrm{min}$ and the $\mathrm{Ca} / \mathrm{P}$ ratio of 1.67 . The average grain diameter of HAp microspheres prepared at the preparation temperature of $973 \mathrm{~K}$ was $1.19 \mu \mathrm{m}$ at the flow rate of $3 \mathrm{~L} / \mathrm{min}$ and $1.05 \mu \mathrm{m}$ at the flow rate of $5 \mathrm{~L} / \mathrm{min}$. In the case of the preparation temperature of $1073 \mathrm{~K}$, the average grain diameter of HAp microsphere was $1.01 \mu \mathrm{m}$ at the flow rate of $3 \mathrm{~L} / \mathrm{min}$ and $1.28 \mu \mathrm{m}$ at $5 \mathrm{~L} / \mathrm{min}$. The size distribution of samples changed depending on the flow rate of carrier gas, and the sample prepared at the flow rate of $5 \mathrm{~L} / \mathrm{min}$ had slightly wider size distribution than that prepared at the flow rate of $3 \mathrm{~L} / \mathrm{min}$. 


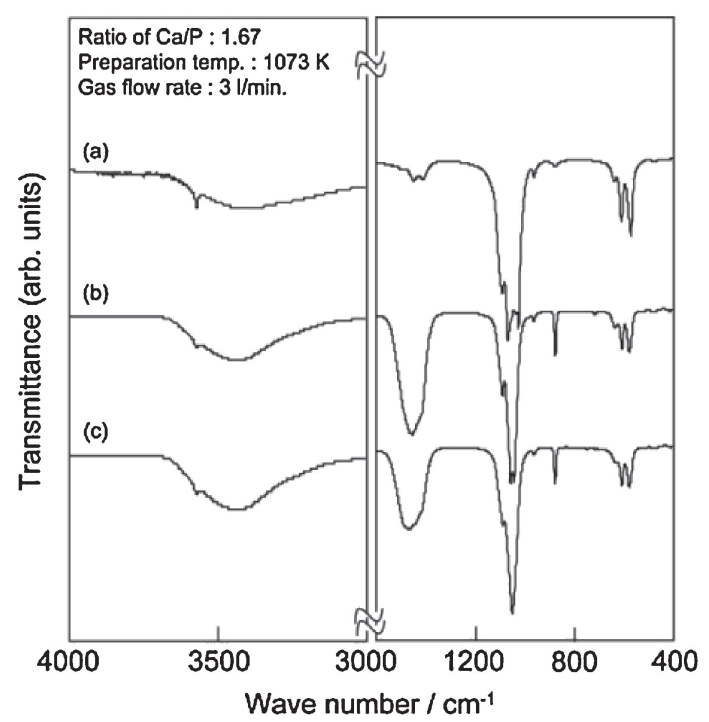

Fig. 4 FT-IR spectra of samples prepared at preparation temperature of $1073 \mathrm{~K}$, flow rate of $\mathrm{Ar}$ gas of $3 \mathrm{~L} / \mathrm{min}, \mathrm{Ca} / \mathrm{P}$ ratio of 1.67 and different Fe ratio; (a) Commercial HAp, (b) $0 \mathrm{~mol} \%$, (c) $1 \mathrm{~mol} \%$.


Fig. 5 SEM of samples prepared at $\mathrm{Ca} / \mathrm{P}$ ratio of 1.67 , flow rate of $\mathrm{Ar}$ gas of $3 \mathrm{~L} / \mathrm{min}$ and different preparation temperature and $\mathrm{Fe}$ ratio; (a) $873 \mathrm{~K}$ and $0 \mathrm{~mol} \%$, (b) $973 \mathrm{~K}$ and $0 \mathrm{~mol} \%$ (c) $1073 \mathrm{~K}$ and $0 \mathrm{~mol} \%$, (d) $1073 \mathrm{~K}$ and $5 \mathrm{~mol} \%$.

\section{Discussion}

The XRD analysis exhibits that the generation phase of sample is able to control by changing the $\mathrm{Ca} / \mathrm{P}$ ratio of precursor and HAp phase were obtained in the relatively wider $\mathrm{Ca} / \mathrm{P}$ ratio from 1.5 to 1.67 . The similar trend was obtained in our previous report. ${ }^{23)}$ Besides, the change in crystallinity was observed at the same $\mathrm{Ca} / \mathrm{P}$ ratio by changing the gas flow rate and preparation temperature as shown in Fig. 2. The crystallinity of sample increased with decreasing gas flow rate and increasing preparation temperature. This means that the flight time of atomized droplets strongly affect for the crystallinity of samples, and the crystallinity of sample is able to be regulated by changing both of gas flow rate and temperature during the preparation. Generally, HAp phase is stable under basis condition, and it has a trouble of degradation behavior in a living body.



Fig. 6 Grain size distribution of HAp microsphere prepared at $\mathrm{Ca} / \mathrm{P}$ ratio of 1.67, preparation temperature of 973 and $1073 \mathrm{~K}$ and flow rate of $\mathrm{Ar}$ gas of 3 and $5 \mathrm{~L} / \mathrm{min}$.

Therefore, improvement of degradability of HAp in such a condition has been conspired by elemental substitution and crystallinity control. The mist process has an advantage of crystallinity controllability by relatively simple method, and this process is enables to prepare the powders with different crystallinity by one step.

The generation of $\mathrm{Ca}(\mathrm{OH})_{2}$ phase as shown in Fig. 3 denotes that the $\mathrm{Ca} / \mathrm{P}$ ratio in droplets moved to high $\mathrm{Ca}$ ratio site, and the generation of $\mathrm{CaClOH}$ phase is caused by a condensation reaction between $\mathrm{Ca}(\mathrm{OH})_{2}$ and $\mathrm{Cl}^{-}$ion. The crystallinity of samples decreased with increasing Fe ratio, and the similar trend of Fe ratio dependency of crystallinity of HAp phase has been observed in our previous study. ${ }^{24)}$ Although the ratio of $\mathrm{Fe}$ in obtained samples increased with increasing additive amount of Fe from the ICP measurement, the actual amount of $\mathrm{Fe}$ in the sample was lower than the targeting composition, and that of sample was 0.9, 1.6 and $2.6 \mathrm{~mol} \%$ for the $\mathrm{Ca}$ of HAp, respectively. Fe-based compounds did not observed in a present study as shown in Fig. 3, and this result suggests the possibility of $\mathrm{Fe}$ substitution into the HAp structure. In order to investigate the substitution of Fe into HAp structure, the measurement of lattice parameter of HAp phase is efficient method. However, there were no trends depending on change in the ratio of Fe. This result is caused by the existence of $\mathrm{CO}_{3}{ }^{2-}$ ions, which derives from the dissolved $\mathrm{CO}_{2}$ into atomized droplets during the synthesis, into HAp structure clarified as shown in Fig. 4. It has been understood that the carbonate-substituted HAp is actually more soluble than pure HAp and increases the local concentration of calcium and phosphate ions. This local alignment of these ions are necessary for new bone formation. ${ }^{25,26)}$ This result suggests that the possibility to use the obtained microsphere as a scaffold of artificial implant due to an excellent biodegradability.

The SEM observation exhibits that the mist process is suitable to prepare the microsphere particles. However the necking of particle was partially observed at low preparation temperature as shown in Fig. 5 (a). It is thought that the necking of particle is mainly caused by the insufficient drying 
of droplets during the preparation. Therefore, it was easily overcome by applying sufficient thermal energy to atomized droplets during transportation by regulating the gas flow rate and preparation temperature. It is generally understood that the morphology of particle changes from solid to hollow structure depending on the density of atomized droplets. In this process, the evaporation and nucleation in droplets firstly occurs by receiving a thermal energy from the external heat source. Then, precipitates move to the surface of droplets caused by the surface tension and then sintered. During that period, solid spherical powder is obtained in the case of high droplet density. In the case of low droplets density, obtained spherical powder has hollow structure due to the low amount of precipitates. Moreover, when the thickness of the wall consisted of precipitates is thin, hollow structure ruptured due to the inside pressure caused by the further evaporation of droplets. Although the solid spherical powder was obtained in a present study, there is a possibility to prepare the hollow HAp spherical powder by choosing the optimum precursor concentration.

The specific surface area of obtained microsphere using BET method was about $80 \mathrm{~m}^{2} / \mathrm{g}$ at the gas flow rate of $5 \mathrm{~L} / \mathrm{min}$ and preparation temperature of $1073 \mathrm{~K}$, and that increased to $130 \mathrm{~m}^{2} / \mathrm{g}$ at gas flow rate of $3 \mathrm{~L} / \mathrm{min}$. Similar trend was observed in the case of $\mathrm{Fe}$ addition. The average particle size of powders is generally estimated from the value of specific surface area. The estimated particle size showed good agreement with the SEM observation and the result of grain size distribution as shown in Fig. 6.

From these results, the mist process is proper technique to prepare the HAp-based microspheres in the particle size range from 0.5 to $5 \mu \mathrm{m}$, and the possibility of co-substitution of $\mathrm{CO}_{3}{ }^{-}$ion with other functional elements was suggested.

\section{Conclusion}

HAp microsphere was prepared by mist process using $0.1 \mathrm{~mol} / \mathrm{L} \mathrm{Ca}\left(\mathrm{NO}_{3}\right)_{2}, \mathrm{FeCl}_{3}$ and $\left(\mathrm{NH}_{4}\right)_{2} \mathrm{HPO}_{4}$ solutions. Obtained powders were HAp in a single phase at the $\mathrm{Ca} / \mathrm{P}$ ratio between 1.5 and 1.67 in all preparation temperature and the flow rate of argon. In the cases of the $\mathrm{Ca} / \mathrm{P}$ ratio of 1.0 and 2.0, obtained powder was mixed phase of HAp and $\mathrm{Ca}_{2} \mathrm{P}_{2} \mathrm{O}_{7}$ or $\mathrm{Ca}(\mathrm{OH})_{2}$. By addition of $\mathrm{Fe}, \mathrm{Ca}(\mathrm{OH})_{2}$ and $\mathrm{CaClOH}$ phases generated and the crystallinity of sample decreased with increasing the ratio of Fe. FT-IR measurement showed the existence of $\mathrm{CO}_{3}{ }^{-}$ion into HAp structure. From the SEM observation, obtained HAp powders had fine microsphere consisted of further smaller primary grains of about several $10 \mathrm{~nm}$. In addition, obtained HAp microsphere had main grain size of about $1 \mu \mathrm{m}$ and size distribution between 0.5 and $5 \mu \mathrm{m}$. From the BET measurement, the HAp microsphere particle had a porous structure and the specific surface area of that was $60-80 \mathrm{~m}^{2} / \mathrm{g}$.

\section{Acknowledgement}

This work was partially supported by Grant-in-Aid for Young Scientists (B) (25870061) from the Japan Society of the Promotion of Science (JSPS).

\section{REFERENCES}

1) S. H. Maxian, J. P. Zawaddsky and M. G. Dunn: J. Biomed. Mater. Res. 28 (1994) 1311-1319.

2) E. L. Solla, J. P. Borrajo, P. Gonzalez, J. Serra, S. Chiussi, B. Leon and J. Garcia Lopez: Appl. Surf. Sci. 253 (2007) 8282-8286.

3) E. S. Ahn, N. J. Gleason, A. Nakahira and J. Y. Ying: Nano Lett. 1 (2001) 149-153.

4) A. Ito, H. Kawamura, M. Otsuka, M. Ikeuchi, H. Ohgushi, K. Ishikawa, K. Onuma, N. Kanzaki, Y. Sogo and N. Ichinose: Mater. Sci. Eng. C 22 (2002) 21-25.

5) H. Murata, K. Shitara, I. Tanaka, A. Nakahira, T. Mizoguchi and K. Matsunaga: J. Phys. Condens. Matter 22 (2010) 384213.

6) K. Matsunaga, H. Murata, T. Mizoguchi and A. Nakahira: Acta Biomater. 6 (2010) 2289-2293.

7) A. Nakahira, S. Nakamura and M. Horimoto: IEEE Trans. Magn. 43 (2007) 2465-2467.

8) J. Wang, T. Nonami and K. Yubata: J. Mater. Sci. Mater. Med. 19 (2008) 2663-2667.

9) K. Nakata, T. Kubo, C. Numako, T. Onoki and A. Nakahira: Mater. Trans. 50 (2009) 1046-1049.

10) L. Medvecký, R. Štulajterová, L. Parilák, J. Trpčevská, J. Ďurišin and S. M. Barinov: Colloids Surf. A Physicochem. Eng. Asp. 281 (2006) 221-229.

11) C. B. Boechat, J.-G. Eon, A. M. Rossi, C. A. de C. Perez and R. A. da S. S. Gil: Phys. Chem. Chem. Phys. 2 (2000) 4225-4230.

12) H. E. L. Madsen: J. Cryst. Growth 310 (2008) 2602-2612.

13) A. Krestou, A. Xenidis and D. Panias: Miner. Eng. 17 (2004) 373-381.

14) I. Smičiklas, S. Dimovic, I. Plecas and M. Mitric: Water Res. 40 (2006) 2267-2274.

15) Q. Wang, W. Huang, D. Wang, B. W. Darvel, D. E. Day and M. N. Rahman: J. Mater. Sci. Mater. Med. 17 (2006) 641-646.

16) I. Kimura, T. Honma and R. E. Riman: J. Ceram. Soc. Japan 115 (2007) 888-893.

17) Q. Peng, L. Ming, C. X. Qu and J. Weng: Key Eng. Mater. 309-311 (2006) 65-68.

18) H.-H. Lee, S.-J. Hong, C.-H. Kim, E.-C. Kim, J.-H. Jang, H.-I. Shin and H.-W. Kim: J. Mater. Sci. Mater. Med. 19 (2008) 3029-3034.

19) J. G. Lu, T. Kawaharamura, H. Nishinaka, Y. Kamada, T. Ohshima and S. Fujita: J. Cryst. Growth 299 (2007) 1-10.

20) P. Singh, A. Kumar, Deepak and D. Kaur: Opt. Mater. 30 (2008) 13161322 .

21) B.-H. Kim, J.-Y. Lee, Y.-H. Choa, M. Higuchi and N. Mizutani: Mater. Sci. Eng. B 107 (2004) 289-294.

22) A. Shinohara and S. Fujita: Jpn. J. Appl. Phys. 47 (2008) 7311-7313.

23) M. Sato and A. Nakahira: J. Jpn. Soc. Powder Powder Metall. 57 (2010) 529-532 (in Japanese).

24) M. Sato and A. Nakahira: J. Ceram. Soc. Japan 121 (2013) 422-425.

25) T. Matsumoto, M. Okazaki, M. Inoue, S. Ode, C. C. Chien, H. Nakao, Y. Hamada and J. Takahashi: J. Biomed. Mater. Res. 60 (2002) 651656.

26) J. E. Barralet, S. Aldred, A. J. Wright and A. G. A. Coombes: J. Biomed. Mater. Res. 60 (2002) 360-367. 